\title{
EVALUATION OF EFFECTING PARAMETERS ON OPTIMUM ARRANGEMENT OF URBAN LAND USES AND ASSESSMENT OF THEIR COMPATIBILITY USING ADJACENCY MATRIX
}

\author{
S. Vaezi ${ }^{\mathrm{a}}$, M.S. Mesgari ${ }^{\mathrm{a}}$, F.Kaviary ${ }^{\mathrm{b}}$ \\ ${ }^{a}$ Dept. of Geomatic Engineering, K. N. Toosi University of Technology, Valy-Asr Street, Mirdamad Cross, Tehran, Iran \\ s.vaezi@mail.kntu.ac.ir \\ ${ }^{a}$ Dept. of Geomatic Engineering, K. N. Toosi University of Technology, Valy-Asr Street, Mirdamad Cross, Tehran, Iran \\ mesgari@kntu.ac.ir \\ ${ }^{b}$ Dept. of Geomatic Engineering, K. N. Toosi University of Technology, Valy-Asr Street, Mirdamad Cross, Tehran, Iran \\ farnaz_kaviari@mail.kntu.ac.ir
}

KEYWORDS: Land-use, Sustainable Urban Development, GIS, Density Levels, Descriptive Analytical Method, Adjacency Matrix

\begin{abstract}
:
Todays, stability of human life is threatened by a set of parameters. So sustainable urban development theory is introduced after the stability theory to protect the urban environment. In recent years, sustainable urban development gains a lot of attraction by different sciences and totally becomes a final target for urban development planners and managers to use resources properly and to establish a balanced relationship among human, community, and nature. Proper distribution of services for decreasing spatial inequalities, promoting the quality of living environment, and approaching an urban stability requires an analytical understanding of the present situation. Understanding the present situation is the first step for making a decision and planning effectively. This paper evaluates effective parameters affecting proper arrangement of land-uses using a descriptive-analytical method, to develop a conceptual framework for understanding of the present situation of urban land-uses, based on the assessment of their compatibility. This study considers not only the local parameters, but also spatial parameters are included in this study. The results indicate that land-uses in the zone considered here are not distributed properly. Considering mentioned parameters and distributing service land-uses effectively cause the better use of these land-uses.
\end{abstract}

\section{INTRODUCTION}

Sustainable urban development is one of the most comprehensive concepts in recent decades.Generally speaking, it means a correct and efficient use of funds, manpower, and natural resources to make an appropriate consumption pattern . An appropriate organizational structure can be satisfactorily obtained from technical features to meet the needs of today's and future generations .So sustainable development not only considers an improvement for today's generation, but it also considers future generations. On the other hand, sustainable development is an equilibrium state among different aspects of development, which is aimed to improve the quality of human life.So sustainable urban development is a form of development which provides the continuous development of cities and urban communities for the future generations. It changes land-uses and density levels to meet the residents' needs for housing, transportation, and welfare services.This planning process makes a city environmentally inhabitable, stable economically, and socially correlated over time. Sustainable development is a solution against physical, social and economic patterns of development. Using that would prevent the destruction of natural resources, an increase of population, injustice and decreasing the quality of current and future people's life. (Isaksson, R., 2006).

In fact, it is a set of tasks which improves the human life with respect to needs of urban community. Thus, cities can be stable only if their infrastructure and land-uses are allocated equivalently. Assessment of urban land-uses plays an important role in a local-spatial organization of a city and approaching the targets of sustainable urban development.

Two directing agents in terms of social welfare and prosperity would be assessed for characterizing the use of ground or every kind of urban activity. According to these two general factors, five criteria including per capita, utility, dependence, access and compatibility are used as criteria of urban land use planning in location of urban functions. These criteria are briefly defined below: per capita is the extent of land dedicated to a specific use of urban facilities with s specified performance level for each individual. (Omer, 2006) Utility refers to compatibility between the land use and its location. Therefore, utility is dependent on many physical, social, economic parameters and etc... (Steiner, 2008). In addition, each urban activity and land use requires access to some other activities in order to increase productivity. In fact, each land use has a set of relations with other land uses that define the affiliation of one land use to other land uses (Taleai, et al., 2007). Access refers to the access of lands to the public transportation network. (Reddy, 2014). And finally, compatibility refers to proximity of land uses that lead to improved performance of one another and separation of land uses that have negative impact on the performance of one another. Therefore, land uses should be juxtaposed in such a way that they can have the most positive interaction with their neighbouring units. (Taleai, et al., 2007) One of the goals of urban land use planning is to provide favourable proximity for land uses and to separate the incompatible uses. Therefore, 
assessment of compatibility between land uses, is an attempt to ensure that with the development of the city, each new use is still a good neighbour to other land uses. To achieve this end, the characteristics of each urban land use, relationships between land uses and the impact land uses on one another, must be fully investigated.

This study is an attempt to investigate the effective factors in proper arrangement of land uses and their impact on the extent of service delivery uses with a descriptive analysis approach. For this purpose, the Delphi method was used to make compatibility matrix that is presented in the next section.

\section{MODELING}

\subsection{Compatibility Matrix}

In order to model the effective parameters in land use arrangements, first a compatibility matrix is formed. In order to achieve a compatibility matrix, first, the existing land uses provided in the map are classified based on the level of performance and type of activity (according to the vision outlined in the comprehensive plan). Afterwards, The Delphi method is used as a framework for making a compatibility matrix and determine the different levels of physical compatibility between different urban land uses. Physical compatibility. Physical compatibility is in fact the compatibility compared to the other adjacent land uses without direct consideration of socio-economic conditions and their emphasis on permanent compatibility and incompatibility aspects, such as noise, pollution, shade, etc. (Taleai, et al., 2007).It should be noted that the Delphi method used in this study is an iterative process to achieve consensus of a group of experts on a particular subject matter and its assessment criteria. This method is particularly used in conditions where there are no standard criteria for assessment. (Shiftan, et al., 2003)

Different compatibility levels including high, medium, neutral, fairly incompatible and totally incompatible are used in this study and each of these levels is defined as follows.

\subsubsection{High Compatible}

When two fully compatible land uses come together, they greatly enhance usability and usefulness of each other.

\subsubsection{Medium Compatible}

When two land uses with low compatibility come together, their effectiveness is slightly increased.

\subsubsection{Neutral}

When two neutral land uses come together, they would have no positive or negative impact on the performance of each other.

\subsubsection{Medium Incompatible}

When two fairly incompatible land uses come together, they lead to decreased usability and usefulness of each other.

\subsubsection{High Incompatible}

Complete non-compatible applications have a very negative impact on the performance of each other and the first priority is that these two applications are not close together
AHP is one of the common methods used to quantify the compatibility matrix. This method is a powerful and flexible decision-making process for the introduction of the priorities of decision-makers and make the best decision when the qualitative and quantitative aspects of a decision are required (Masoomi, z., 2013)

Different compatibility levels for different land uses are shown in Table 1.

\begin{tabular}{|c|c|c|c|c|c|c|c|c|c|c|c|}
\hline W & RP & I & $\begin{array}{l}\mathrm{U} \\
\mathrm{F}\end{array}$ & At & $\begin{array}{c}\text { C } \\
M\end{array}$ & $\mathrm{Ad}$ & $\mathrm{T}$ & E & C & $\mathrm{R}$ & \\
\hline \multirow[t]{11}{*}{$\mathrm{N}$} & $\begin{array}{l}\mathrm{H} \\
\mathrm{C}\end{array}$ & MI & MI & $\begin{array}{l}\mathrm{H} \\
\mathrm{C}\end{array}$ & $\begin{array}{l}\mathrm{M} \\
\mathrm{C}\end{array}$ & MI & $\begin{array}{l}\mathrm{H} \\
\mathrm{C}\end{array}$ & MI & $\begin{array}{l}\mathrm{H} \\
\mathrm{C}\end{array}$ & $\begin{array}{l}\mathrm{H} \\
\mathrm{C}\end{array}$ & $\mathrm{R}$ \\
\hline & $\begin{array}{l}\mathrm{H} \\
\mathrm{C}\end{array}$ & MI & MI & $\begin{array}{l}\mathrm{H} \\
\mathrm{C}\end{array}$ & $\mathrm{N}$ & $\begin{array}{l}\mathrm{M} \\
\mathrm{C}\end{array}$ & $\begin{array}{l}\mathrm{H} \\
\mathrm{C}\end{array}$ & $\begin{array}{l}\mathrm{H} \\
\mathrm{C}\end{array}$ & $\begin{array}{l}\mathrm{H} \\
\mathrm{C}\end{array}$ & $\begin{array}{l}\mathrm{H} \\
\mathrm{C}\end{array}$ & C \\
\hline & & MI & MI & $\begin{array}{l}\mathrm{H} \\
\mathrm{C}\end{array}$ & $\mathrm{N}$ & MI & MI & HI & $\begin{array}{l}\mathrm{H} \\
\mathrm{C}\end{array}$ & $\begin{array}{r}\text { M } \\
\text { I }\end{array}$ & $\mathrm{El}$ \\
\hline & & & MI & MI & $\begin{array}{l}\mathrm{M} \\
\mathrm{C}\end{array}$ & $\begin{array}{l}\mathrm{H} \\
\mathrm{C}\end{array}$ & $\begin{array}{l}\mathrm{H} \\
\mathrm{C}\end{array}$ & MI & $\begin{array}{l}\mathrm{H} \\
\mathrm{C}\end{array}$ & $\begin{array}{l}\mathrm{H} \\
\mathrm{C}\end{array}$ & $\mathrm{T}$ \\
\hline & & & & $\mathrm{N}$ & $\mathrm{N}$ & $\begin{array}{l}\mathrm{H} \\
\mathrm{C}\end{array}$ & $\begin{array}{l}\mathrm{H} \\
\mathrm{C}\end{array}$ & MI & $\begin{array}{l}\mathrm{M} \\
\mathrm{C}\end{array}$ & $\begin{array}{r}\text { M } \\
\text { I }\end{array}$ & $\mathrm{Ad}$ \\
\hline & & & & & HI & $\mathrm{N}$ & $\begin{array}{l}\mathrm{M} \\
\mathrm{C}\end{array}$ & $\mathrm{N}$ & $\mathrm{N}$ & $\begin{array}{l}\mathrm{M} \\
\mathrm{C}\end{array}$ & $\begin{array}{l}\mathrm{C} \\
\mathrm{M}\end{array}$ \\
\hline & & & & & & $\mathrm{N}$ & MI & $\begin{array}{l}\mathrm{H} \\
\mathrm{C}\end{array}$ & $\begin{array}{l}\mathrm{H} \\
\mathrm{C}\end{array}$ & $\begin{array}{l}\mathrm{H} \\
\mathrm{C}\end{array}$ & At \\
\hline & & & & & & & MI & MI & MI & $\begin{array}{r}\text { M } \\
\text { I }\end{array}$ & $\begin{array}{l}\mathrm{U} \\
\mathrm{F}\end{array}$ \\
\hline & & & & & & & & MI & MI & $\begin{array}{r}\text { M } \\
\text { I }\end{array}$ & I \\
\hline & & & & & & & & & $\begin{array}{l}\mathrm{H} \\
\mathrm{C}\end{array}$ & $\begin{array}{l}\mathrm{H} \\
\mathrm{C}\end{array}$ & $\mathrm{RP}$ \\
\hline & & & & & & & & & & $\mathrm{N}$ & $\mathrm{W}$ \\
\hline
\end{tabular}

Table 1. Different compatibility levels for different land uses $\mathrm{R}$ as Residential, $\mathrm{C}$ as Commercial, E as Educational, T as Therapeutic, Ad as Administrative, CM as Cultural and Mosque, A as Athletic, UF as Urban Facilities, I as Industrial, $\mathrm{RP}$ as Recreation and Park, W as Wasteland. (Derived from Masoomi,2014)

Although, urban planners use compatibility matrix at the level of urban zones to determine future land use in developing regions, in this study, compatibility matrix is used to assess the compatibility between the existing detailed uses in the constructed urban areas and at the level of building plaques.

\subsection{Study Area}

The study area is the central area of the city of Abhar, Zanjan which is located $90 \mathrm{~km}$ south of East Zanjan and 230 kilometers West of Tehran. Abhar is 1,540 m above sea level, with 87, 396 inhabitants in 1390, was considered the second most populated city in the province of Zanjan, after the city of Zanjan. In this study, building plaque map and subject information regarding the use of each plate, as needed baseline data, are provided and prepared for storage in GIS software.

Figure 1 shows the map of Abhar. The center of Abhar show in figure 2, which there are a lot of different land_use considered 
The International Archives of the Photogrammetry, Remote Sensing and Spatial Information Sciences, Volume XL-1/W5, 2015 International Conference on Sensors \& Models in Remote Sensing \& Photogrammetry, 23-25 Nov 2015, Kish Island, Iran

in this study, is used for implementing and calculating the compatibility.

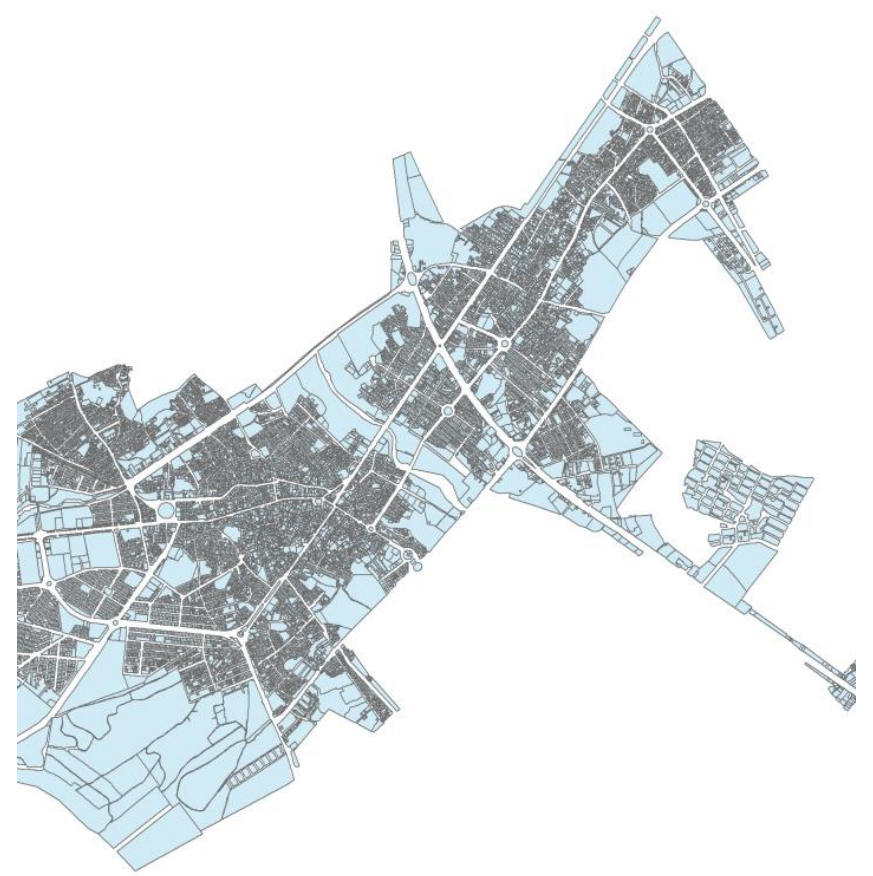

2505001,000 Meters

Figure 1. Abhar city map. Different applications show with different colours

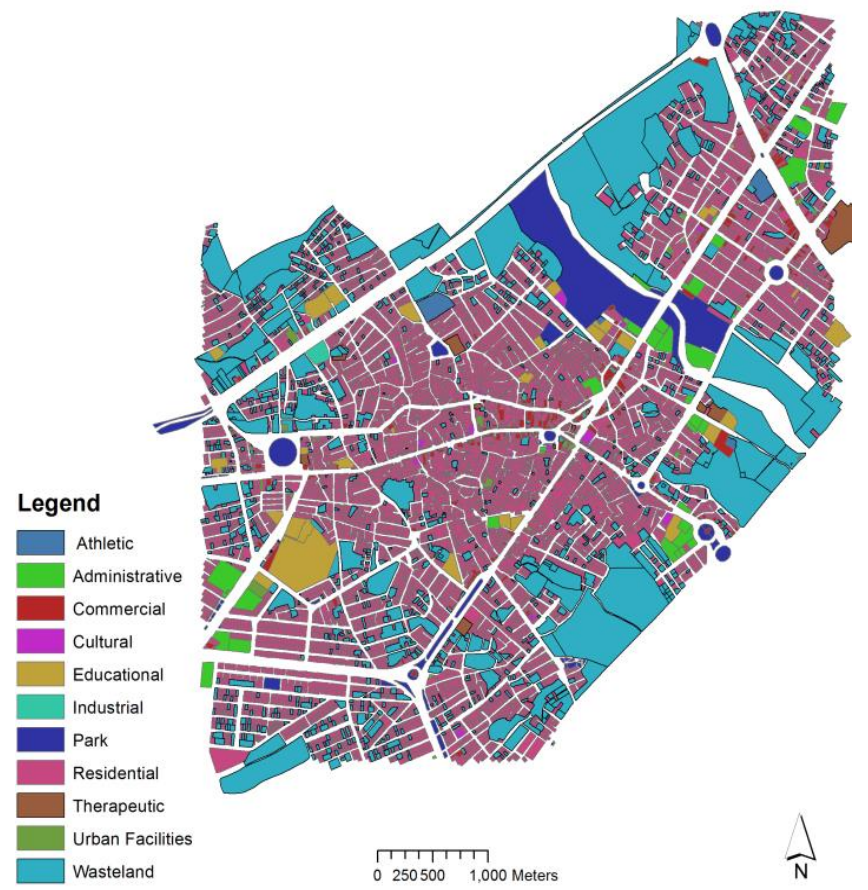

Figure 2. Center of Abhar, which there are different land-use considered in this study

Given that in this study, shift from compatibility levels to incompatibility levels is more important than shift from incompatibility levels to compatibility levels, the AHP results are finally standardized as Table2

\begin{tabular}{|c|c|}
\hline $\begin{array}{c}\text { Standardized } \\
\text { values }\end{array}$ & compatibility levels \\
\hline 0.43 & High Compatible \\
\hline 0.28 & Medium Compatible \\
\hline 0.18 & Neutral \\
\hline 0.08 & $\begin{array}{c}\text { Medium } \\
\text { Incompatible }\end{array}$ \\
\hline 0.04 & High Incompatible \\
\hline
\end{tabular}

Table 2. The AHP standardized results

It should be noted that the following equation is used to calculate the compatibility number for each plaque. (Masoomi, 2014)

$$
\mathrm{F}=\left(w_{1} \frac{1}{n} \sum_{i=1}^{n}\left(\frac{1}{n_{i}} \sum_{j=1}^{n_{i}}\left(\operatorname{Comp}_{i j}\right)\right)+w_{2} \min _{i j}\left(\operatorname{Comp}_{i j}\right)\right.
$$

$$
\text { Where } \begin{aligned}
i & =\text { Plaque } \quad j=\text { Plaque neighbours } \\
n_{i} & =\text { Number of plaque neighbours } \\
w_{1} & =\text { Total compatibility factor } \\
w_{2} & =\text { least compatibility factor } \\
& \quad n=\text { number of total plaque }
\end{aligned}
$$

$\operatorname{Comp}_{i j}=$ Standarded compatibility of the plaque $\mathrm{i}$ with the plaque $\mathrm{j}$

In order to define neighborhood, a circle with a radius of 12 meters was drawn and the plaques located within this radius were regarded as neighbor plaques. In this study, the weights are set to 1 . The first part of equation 1 calculates the sum of compatibility between plaque 1 and adjacent plaques. The second part resolves the compensation of sum of the compatibilities to an acceptable level, by considering the greater effect of minimum compatibilities.

\section{DISCUSSION AND CONCLUSION}

Assessment of the study area's land use in terms of compatibility was conducted using Python in the ArcGIS environment. The results showed that in the study area a total of 7904 units have high incompatible and medium incompatible uses and a total of 4598 units have compatible and high compatible uses compared to the neighboring plaques uses, which could have a positive impact on the performance of neighboring land uses. Results are shown in Figure 2 


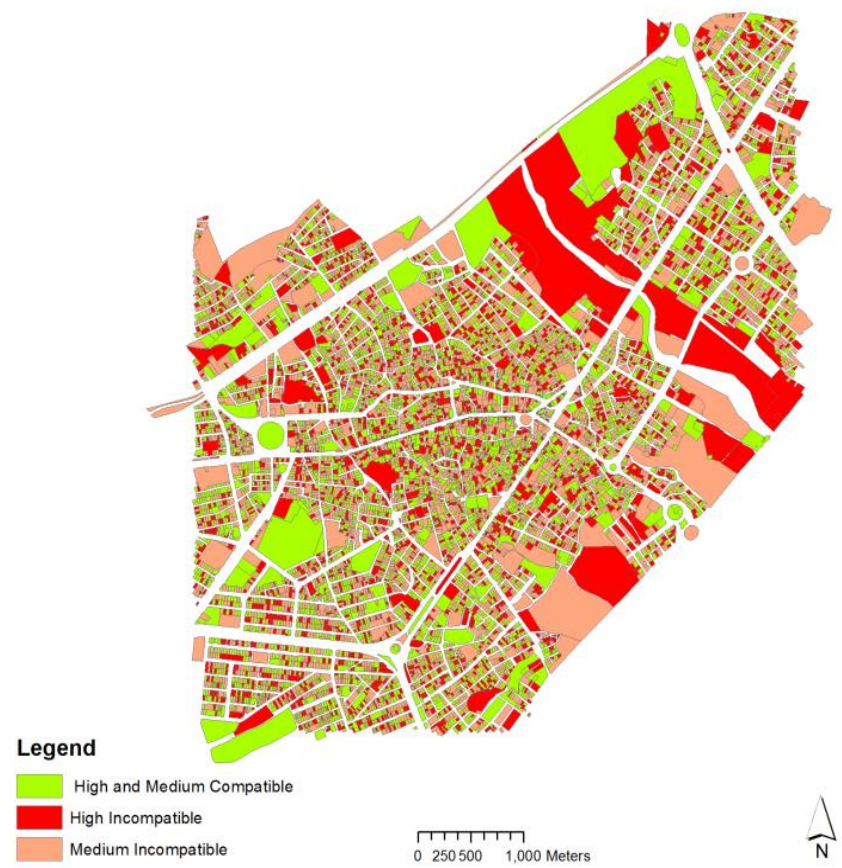

Figure 3. Results of Analysis
Omer, Itzhak. "Evaluating accessibility using house-level data: A spatial equity perspective." Computers, environment and urban systems 30.3 (2006): 254-274.

Reddy,P.B. (2014) planning for future urban development: land use analysis. Dehli,India: Jawaharlal Nehru Technological Univercity, Hyderabad

Shiftan, Yoram, Sigal Kaplan, and Shalom Hakkert. "Scenario building as a tool for planning a sustainable transportation system." Transportation Research Part D: Transport and Environment 8.5 (2003): 323-342.

Steiner,F. (2008). The Living Landscape: An Ecological Approach to Landscape Planning (second ed). New York: Mc Graw Hills

Taleai, Mohammad, et al. "Evaluating the compatibility of multi-functional and intensive urban land uses." International Journal of Applied Earth Observation and Geoinformation 9.4 (2007): 375-391.
Considering the above-mentioned parameters and better substitution of service uses, it would be possible to take more useful advantage of them. Use of GIS system's spatial analysis can significantly help to analyze the current situation of land uses in this region. In addition, consideration of the proposed indexes in urban designing and changes in the property uses have negative impact on the performance of neighboring plaques and in fact are placed in incompatible and fairly incompatible category of property use. Moreover, substitution of more suitable uses, not only leads to reduction of energy consumption and development of a sustainable economy, but also leads to development of a healthier environment, more comprehensive justice, and improved quality of life. And can provide a way for the current cities to achieve sustainability in all arenas.

\section{REFERENCES}

Isaksson, R. (2006), “Total quality management for sustainable development Process based system models",Business Process Management Journal,Vol. 12 No. 5 ,pp. 632-645.

Masoomi.Z. "Modeling physical impacts of urban land-use change using optimization algorithms and spatial analyses." $\mathrm{PhD}$ Thesis in Geographic Information Systems, Khaje Nasir Toosi Univercity of Technology(2014)

Masoomi, Zohreh, Mohammad Sadi Mesgari, and Majid Hamrah. "Allocation of urban land uses by Multi-Objective Particle Swarm Optimization algorithm."International Journal of Geographical Information Science 27.3 (2013): 542-566. 